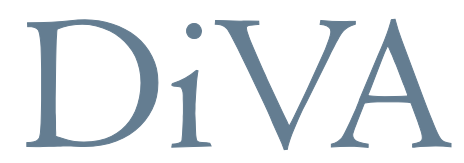

http://uu.diva-portal.org

This is an author produced version of a paper published in Thin Solid Films. This paper has been peer-reviewed but does not include the final publisher proofcorrections or journal pagination.

Citation for the published paper:

Maghanga, C.M., Niklasson, G., Granqvist, C-G.

"Optical Properties of Sputter Deposited Transparent and Conducting $\mathrm{TiO}_{2}: \mathrm{Nb}$

Films"

Thin Solid Films, 2009, Vol. 518, Issue 4: 1254-1258

URL: http://dx.doi.org/10.1016/j.tsf.2009.06.064

Access to the published version may require subscription.

Published with permission from: Elsevier 


\title{
Optical Properties of Sputter Deposited Transparent and Conducting $\mathrm{TiO}_{2}$ :Nb Films
}

\author{
C. M. Maghanga*, G. A. Niklasson and C. G. Granqvist \\ Department of Engineering Sciences, The Angström Laboratory, P. O. Box 534, \\ SE-75121 Uppsala, Sweden
}

\begin{abstract}
Transparent and conducting thin films of $\mathrm{TiO}_{2}: \mathrm{Nb}$ were prepared on glass by reactive $\mathrm{dc}$ magnetron sputtering in $\mathrm{Ar}+\mathrm{O}_{2}$. Post deposition annealing in vacuum at $450{ }^{\circ} \mathrm{C}$ led to good electrical conductivity and optical transparency. The optical properties in the subbandgap region were in good agreement with Drude free electron theory, which accounts for intraband absorption. The band gap of the films was found to be in the range of 3.3 to $3.5 \mathrm{eV}$ and signifies the onset of interband absorption. Electrical conductivities in the $10^{-3}$ $\Omega \mathrm{cm}$ range were obtained both from dc electrical measurements and from analysis of the optical measurements.
\end{abstract}

*Corresponding author. Permanent address: Kabarak University, P. O. Private Bag 20157, Kabarak, Kenya. Email: christopher.maghanga@yahoo.com 


\section{Introduction}

Transparent conducting oxides (TCOs) are crucial in today's technology for applications such as solar energy utilization and energy efficiency, transparent electronics, lighting, and many more [1]. The most widely used and studied TCOs are $\operatorname{In}_{2} \mathrm{O}_{3}: \mathrm{Sn}, \mathrm{ZnO}: \mathrm{Al}$, $\mathrm{ZnO}: \mathrm{Ga}$, and $\mathrm{SnO}_{2}: \mathrm{F}$ [2]. All of them have limitations such as uncomfortably narrow ranges of deposition parameters, requirements of high substrate temperatures, cost (for In), etc., and viable alternatives have been sought for many years. A recently discovered alternative is doped $\mathrm{TiO}_{2}[3,4]$, which is different from the other TCOs in that conduction takes place in the $d$-band rather than in the $s$-band [5,6]. Earlier work on TCO-type $\mathrm{TiO}_{2}: \mathrm{Nb}$ has employed pulsed laser deposition [3,7-14], rf magnetron sputtering [15], and dc magnetron sputtering [11,16-18]. The sputtered films were post-treated in $\mathrm{H}_{2}$ or vacuum at 400 to $600{ }^{\circ} \mathrm{C}$ for $1 \mathrm{~h}$, in order to exhibit favorable electrical properties.

In this paper we present a thorough analysis of the optical properties of sputtered $\mathrm{Nb}$-doped $\mathrm{TiO}_{2}$ films. We show that the optical properties in the sub-band gap region can be accounted for by Drude free electron theory. We also compare the electrical resistivity obtained from dc electrical measurements and optical measurements and find good agreement. The new $\mathrm{TiO}_{2}$-based TCOs are of particular interest since they are based on readily available constituents and exhibit favorable optical and electrical properties.

\section{Films}

\subsection{Deposition}

Thin films of $\mathrm{Ti}_{1-\mathrm{x}} \mathrm{Nb}_{\mathrm{x}} \mathrm{O}_{2}$ were made by dual-target reactive dc magnetron sputtering following procedures described elsewhere [17]. Sputtering took place in $\mathrm{Ar}+\mathrm{O}_{2}$, having at least $99.995 \%$ purity, mixed so that the $\mathrm{Ar} / \mathrm{O}_{2}$ ratio was $60 / 3.5$. The sputtering pressure was set at 8.5 mTorr. Sputtering was conducted with the power to the Ti target being $220 \mathrm{~W}$ and the power to the $\mathrm{Nb}$ target lying between zero and $45 \mathrm{~W}$ in order to make films with different $\mathrm{Nb}$ content. A small amount of $\mathrm{H}_{2}$ was added in order to avoid target poisoning and allow stable sputtering conditions. Sputtering was performed onto 
glass (microscope slides) and Si plates positioned $\sim 13 \mathrm{~cm}$ below the targets on a rotatable holder. The substrates were maintained at $330{ }^{\circ} \mathrm{C}$ during sputtering as measured by a thermocouple. After the deposition, the films were first allowed to cool within the sputter unit and were then vacuum annealed at $450{ }^{\circ} \mathrm{C}$ for 30 minutes in the deposition chamber. Deposition rate $r$ was inferred from sputtering time and film thickness, as measured by surface profilometry. The films were between 210 and $293 \mathrm{~nm}$ in thickness and were deposited at a rate ranging from 7 to $10 \mathrm{~nm} / \mathrm{s}$.

\subsection{Structural characterization}

The film structure was investigated by X-ray diffraction (XRD) using a Siemens D5000 instrument operating with $\mathrm{CuK}_{\alpha}$ radiation. Figure 1 shows data for $\mathrm{TiO}_{2}$ films with different $\mathrm{Nb}$ contents, after annealing at $450{ }^{\circ} \mathrm{C}$. The various diffraction peaks could be unambiguously assigned to reflections corresponding to the anatase and rutile phases of $\mathrm{TiO}_{2}$ (JCPDS data cards 00-021-1272 and 00-21-1276, respectively). The prominence of the diffraction peak at $2 \theta=25.2^{\circ}$ points at preferential orientation along the (004) direction.

The XRD data show that the crystallinity was improved upon annealing, and then the presence of a diffraction peak at $2 \theta \approx 27^{\circ}$ shows that the undoped film contains some rutile. The presence of $\mathrm{Nb}$ seems to impede the formation of this phase, and nothing but anatase is evident already when the $\mathrm{Nb}$ content is as small as 1.3 at. \%.

Crystallite sizes were estimated from the XRD by using the well known DebyeScherrer formula, i.e., $D=\left(0.9 \lambda_{x}\right) /(\beta \cos \theta)$, where $D$ is the diameter of the crystallites forming the film, $\lambda_{x}$ is the wavelength of the X-ray line, and $\beta$ is the full width at half maximum of the XRD peak. We found $D$ to be in the range 21 to $28 \mathrm{~nm}$ for the studied films.

The composition of the films was determined by Rutherford Backscattering Spectrometry and Elastic Recoil Detection Analysis. The results of these two methods 
were consistent and gave an accurate determination of the atomic $\%$ of $\mathrm{Nb}$, as specified in the figures and text, as well as a Ti/O ratio of 0.42

\section{Optical and electrical data}

\subsection{Transmittance and reflectance}

Spectral normal transmittance $T(\lambda)$ and near-normal reflectance $R(\lambda)$ were recorded in the $300<\lambda<2500 \mathrm{~nm}$ wavelength range by use of a Perkin-Elmer Lambda 900 doublebeam spectrophotometer and having a barium sulphate film as reflectance standard. Figure 2 shows data for zero, intermediate, and high $\mathrm{Nb}$ contents. It is seen that the infrared transmittance is suppressed in $\mathrm{TiO}_{2}$ films with more than 2 at. $\% \mathrm{Nb}$.

\subsection{Analysis of optical data}

The spectrophotometric reflectance and transmittance data were compared with computations starting from a model for the dielectric susceptibility of the films. Such a model should take into account the band gap at short wavelengths (high frequencies), as well as the response of the conduction electrons at longer wavelengths (lower frequencies). For frequencies below the band gap frequency we used the Drude model, which accounts for intraband transitions of the conduction electrons [20]. The dielectric susceptibility, expressed as a function of frequency $\omega$, according to this model can be written as [20]

$$
\chi_{D}(\omega)=\frac{\Omega_{p}^{2}}{\omega^{2}+i \omega \Omega_{r}},
$$

where $\Omega_{\mathrm{p}}$ is the plasma frequency and $\Omega_{\gamma}$ is the relaxation frequency. In order to account for the onset of absorption in the band gap region, we used the Brendel-Bormann expression [21] to model the influence of interband transitions. It is a weighted superposition of an infinite number of Lorentz oscillators and has been found to be applicable to interband absorption in a number of materials [22]. The interband dielectric susceptibility is given by 


$$
\chi_{B}=\frac{1}{\sqrt{2 \pi} \sigma} \int_{-\infty}^{\infty} \exp \left(-\frac{\left(x-\Omega_{o}\right)^{2}}{2 \sigma^{2}}\right) \frac{\Omega_{f}^{2}}{x^{2}-\omega^{2}+i \omega \Omega_{\Gamma}} d x,
$$

where $\Omega_{0}$ is the resonance frequency, $\Omega_{\mathrm{f}}$ is the oscillator strength parameter, $\Omega_{\Gamma}$ is the damping and $\sigma$ denotes the width of the distribution. The total dielectric permittivity can then be written as

$$
\chi=1+\chi_{B}+\chi_{D} .
$$

The parameters in the above models were determined from the best fit between computed and experimental data, using commercial software [23]. In this paper we focus on the frequency region below the band gap and report only the Drude parameters in Eq. (1), from which we can obtain the conduction electron concentration

$$
n=\frac{\varepsilon_{o} m \Omega_{p}{ }^{2}}{e^{2}},
$$

and the dc resistivity

$$
\rho=\frac{\Omega_{r}}{\varepsilon_{o} \Omega_{p}^{2}} .
$$

Here $e$ and $m$ denote the charge and effective mass of an electron, and $\varepsilon_{0}$ is the dielectric permittivity of vacuum. Figure 3 shows a comparison between experimental spectra on $R(\lambda)$ and $T(\lambda)$ with the best fit obtained with the Drude-Brendel model in Eqs. (1)-(3). The agreement is generally good, especially at long wavelengths (low frequencies) where the Drude term dominates. Some discrepancies, pointing at the approximate nature of Eq. (2), occur in the band gap region for samples with more than 3 at. \% Nb.

The fit between experiments and computations is sufficiently good so that dispersion analysis can be used to extract spectral refractive index $n(\lambda)$ and extinction coefficient $k(\lambda)$. The fit parameters of the Drude-Brendel model give directly the optical constants of the film under study. The obtained optical constants have been verified by comparison with other methods, which do not depend on the specific model chosen for the dielectric susceptibility. Figure 4 a shows the refractive index for a film with 3.7 at $\%$ 
$\mathrm{Nb}$ at $\lambda<800 \mathrm{~nm}$. Excellent agreement was found between the values obtained by our dispersion analysis and those of the interference fringe method of Swanepoel [24]. In addition, Fig. $4 \mathrm{~b}$ shows excellent agreement between $k(\lambda)$ from dispersion analysis and from the approximate relation of Hong [25], i.e.,

$$
\alpha(\lambda)=\frac{\ln ((1-R(\lambda)) / T(\lambda))}{d},
$$

where $\alpha(\lambda)=4 \pi k(\lambda) / \lambda$ is the absorption coefficient. We conclude that accurate values of refractive index $n(\lambda)$ and extinction coefficient $k(\lambda)$ are obtained by our dispersion analysis.

Figure 5 shows spectral refractive index $n(\lambda)$ and extinction coefficient $k(\lambda)$ for $\mathrm{TiO}_{2}$ and for $\mathrm{TiO}_{2}: \mathrm{Nb}$ with two different doping levels. Figure 5 shows that the undoped film exhibits a dielectric behaviour with $n \approx 2.2$ irrespectively of wavelength for $\lambda>500$ $\mathrm{nm}$. For the $\mathrm{Nb}$ doped films, the optical constants are qualitatively different. In this case $k(\lambda)$ increases for increasing $\lambda$, as expected for a metallic material, while $n(\lambda)$ drops gently towards larger $\lambda$. These effects increase in magnitude with increasing doping level of $\mathrm{Nb}$.

\subsection{Band gap}

The optical band gap $E_{g}$ was evaluated from the standard expression [19]

$$
\alpha E \propto\left(E-E_{g}\right)^{m},
$$

where $E$ is photon energy, and $m=2$ accounts for the fact that the indirect allowed transitions across the band gap are expected to dominate. Figure 6 shows data on $(\alpha E)^{1 / 2}$ vs. $E$ for a $\mathrm{TiO}_{2}$ film; a band gap of $3.36 \mathrm{eV}$ is obtained from the intersection of the fitted straight line and the abscissa. Band gaps for films annealed at different temperatures and containing different amounts of $\mathrm{Nb}$ were not very different; they all lay in the range 3.35 to $3.51 \mathrm{eV}$. 


\subsection{Electrical conductivity}

The dc resistivity of the films was determined by the van der Pauw method [26] applied to $4 \mathrm{x} 4 \mathrm{~mm}^{2}$ samples with sputter deposited $\mathrm{Au}$ contacts. Undoped $\mathrm{TiO}_{2}$ films had a resistivity of $\sim 300 \Omega \mathrm{cm}$. $\mathrm{Nb}$ doping made the resistivity drop monotonically for increasing doping from $\sim 1.2 \times 10^{-2} \Omega \mathrm{cm}$ for 1.3 at. $\% \mathrm{Nb}$ to $1.9 \times 10^{-3} \Omega \mathrm{cm}$ for 4.9 at. $\%$ $\mathrm{Nb}$. We now compare these values to those computed from the optical measurements using Eqs. (4) and (5) and given in Table I. It is seen that the carrier density is increased from $2.5 \times 10^{20}$ to $2.4 \times 10^{21} \mathrm{~cm}^{-3}$ as the $\mathrm{Nb}$ content goes from 1.3 at. $\%$ to 4.9 at. $\%$. These results are in good agreement with literature data for $\mathrm{TiO}_{2}: \mathrm{Nb}$ films made by sputtering $[15,16]$. Furthermore, the resistivity obtained from the analysis of the optical measurements is close to the measured dc value. This indicates that the Drude free electron behaviour persists to zero frequency with very little, if any, dispersion in the resistivity.

\section{Discussion and conclusion}

This paper has demonstrated that TCO-type $\mathrm{TiO}_{2}: \mathrm{Nb}$ can be made by reactive $\mathrm{dc}$ magnetron sputtering. Annealing at $450{ }^{\circ} \mathrm{C}$ led to electrical conduction while optical transparency was preserved, thus verifying recent work from a few laboratories showing that $\mathrm{TiO}_{2}: \mathrm{Nb}$ can serve as a transparent conductor. The optical properties were well described by Drude free electron theory for frequencies below the band gap. Good agreement was found between measured dc resistivity and the resistivity obtained from optical data.

Acknowledgement. This paper was supported by a grant from the Swedish Research Council (VR). One of the authors (C. M. M.) would like to thank the International Science Programme of Uppsala University for a scholarship. 


\section{References}

[1] D. S. Ginley, H. Hosono and D Paine, editors, Transparent Conductors: Materials, Processing and Applications (Springer, Berlin, Germany, 2008) to be published.

[2] C. G. Granqvist, Solar Energy Mater. Solar Cells 91 (2007) 1529; in Ref. 1.

[3] Y. Furubayashi, T. Hitosugi, Y. Yamamoto, K. Inaba, G. Kinoda, Y. Hirose, T. Shimada and T. Hasegawa, Appl. Phys. Lett. 86 (2007) 252101; Y. Furubayashi, T. Hitosugi and T. Hasegawa, Appl. Phys. Lett. 88 (2006) 226103.

[4] T. Hitosugi, Y. Furubayashi, A. Ueda, K. Itabashi, K. Inaba, Y. Hirose, G. Kinoda, Y. Yamamoto, T. Shimada and T. Hasegawa, Jpn. J. Appl. Phys. 44 (2005) L1063.

[5] J. Robertson, Phys. Stat. Sol. B 245 (2008) 1026.

[6] X. D. Liu, E. Y. Jiang, Z. Q. Li and Q. G. Song, Appl. Phys. Lett. 92 (2008) 252104.

[7] Y. Furubayashi, T. Hitosugi, Y. Yamamoto, Y. Hirose, G. Kinoda, K. Inaba, T. Shimada and T. Hasegawa, Thin Solid Films 496 (2006) 157.

[8] T. L. Chen, Y. Furubayashi, Y. Hirose, T. Hitosugi, T. Shimada and T. Hasegawa, J. Phys. D: Appl. Phys. 40 (2007) 5961.

[9] Y. Furubayashi, N. Yamada, Y. Hirose, Y. Yamamoto, M. Otani, T. Hitosugi, T. Shimada and T. Hasegawa, J. Appl. Phys. 101 (2007) 093705.

[10] T. Hitosugi, A. Ueda, Y. Furubayashi, Y. Hirose, S. Konuma, T. Shimada and T. Hasegawa, Jpn. J. Appl. Phys. 46 (2007) L86.

[11] T. Hitosugi, A. Ueda, S. Nakao, N. Yamada, Y. Furubayashi, Y. Hirose, T. Shimada and T. Hasegawa, Appl. Phys. Lett. 90 (2007) 212106; T. Hitosugi, A. Ueda, S. Nakao, N. Yamada, Y. Furubayashi, Y. Hirose, S. Konuma, T. Shimada and T. Hasegawa, Thin Solid Films 516 (2008) 5750; T. Hitosugi, N. Yamada, S. Nakao, K. Hatabayashi, T. Shimada and T. Hasegawa, J. Vac. Sci. Technol. A 26 (2008) 1027.

[12] S. Okazaki, N. Okazaki, Y. Hirose, Y. Furubayashi, T. Hitosugi, T. Shimada and T. Hasegawa, Appl. Surf. Sci. 254 (2007) 757. 
[13] S. X. Zhang, S. Dhar, W. Yu, H. Xu, S. B. Ogale and T. Venkatesan, Appl. Phys. Lett. 91 (2007) 112113; S. X. Zhang, D. C. Kundaliya, W. Yu, S. Dhar, S. Y. Young, L.G. Salamanca-Riba, S. B. Ogale, R. D. Vispute and T. Venkatesan, J. Appl. Phys. 102 (2007) 013701.

[14] M. S. Dabney, M. F. A. M. van Hest, C. W. Teplin, S. P. Arenkiel, J. D. Perkins and D. S. Ginley, Thin Solid Films 516 (2008) 4133.

[15] M. A. Gillispie, M. F. A. M. van Hest, M. S. Dabney, J. D. Perkins and D. S. Ginley, J. Appl. Phys. 101 (2007) 033125; J. Mater. Res. 22 (2007) 2832.

[16] N. Yamada, T. Hitosugi, N. L. H. Hoang, Y. Furubayashi, Y. Hirose, T. Shimada and T. Hasegawa, Jpn. J. Appl. Phys. 46 (2007) 5275; N. Yamada, T. Hitosugi, N. L. H. Hoang, Y. Furubayashi, Y. Hirose, S. Konuma, T. Shimada and T. Hasegawa, Thin Solid Films 516 (2008) 5754.

[17] C. M. Maghanga, J. Jensen, G. A. Niklasson, C. G. Granqvist and M. Mwamburi, Solar Energy Mater. Solar Cells, to be published.

[18] Y. Sato, H. Akizuki, T. Kamiyama and Y. Shigesato, Thin Solid Films 516 (2008) 5758 .

[19] C. G. Granqvist, Handbook of Inorganic Electrochromic Materials (Elsevier, Amsterdam, The Netherlands, 1995), pp. 265-275.

[20] F. Wooten, Optical Properties of Solids, (Academic, New York, 1972), pp. 52-55.

[21] R. Brendel and D. Bormann, J. Appl. Phys. 71 (1992) 1-6.

[22] A. D. Rakic', A. B. Djurisic', J. M. Elazar and M. L., Majewski, Appl. Opt. 37 (1998) 5271.

[23] W. Theiss, in: M. Theiss (Ed.), Scout Thin Film Analysis Software Handbook, Hardand Software, Aachen, Germany, www.mtheiss.com

[24] R. Swanepoel, J. Phys. E. Sci. Instrum. 16 (1983) 1214.

[25] W.Q. Hong, J. Phys. D: Appl. Phys. 22 (1989) 1384.

[26] L. J. van der Pauw, Philips Tech. Rev. 20 (1958) 220. 


\section{List of Figures}

Fig. 1. X-ray diffractograms for $\mathrm{Ti}_{1-x} \mathrm{Nb}_{x} \mathrm{O}_{2}$ films made by sputtering . The peaks are assigned to the anatase (A) and rutile (R) structures. The $\mathrm{Nb}$ content is given in atomic percent.

Fig. 2. Spectral transmittance and reflectance for $\mathrm{TiO}_{2}$ and $\mathrm{TiO}_{2}: \mathrm{Nb}$ films, with at. $\% \mathrm{Nb}$ as shown in the inset, after annealing at $450{ }^{\circ} \mathrm{C}$ in vacuum.

Fig. 3. Experimental spectral reflectance and transmittance for annealed $\mathrm{TiO}_{2}$ samples with (a) 1.3 at. $\% \mathrm{Nb}$ and (b) 2.1 at. $\% \mathrm{Nb}$. Experimental data are shown by dashed lines and calculations, with the model described in the text, are shown by full lines.

Figure 4: Refractive index (a) and extinction coefficient (b) for an annealed $\mathrm{TiO}_{2}: \mathrm{Nb}$ film containing 3.7 at. \% Nb. Values from dispersion analysis using a Drude-Brendel model are compared to those obtained from other model-independent methods, as given in the figure.

Fig. 5. Spectral refractive index (a) and extinction coefficient (b) for $\mathrm{Ti}_{1-x} \mathrm{Nb}_{x} \mathrm{O}_{2}$ films made by sputtering. Concentrations in at. \% of $\mathrm{Nb}$ are given in the figures.

Fig. 6. $(\alpha E)^{1 / 2} v s$. photon energy $E$, where $\alpha$ is the absorption coefficient, for a $\mathrm{TiO}_{2}$ film annealed at $450{ }^{\circ} \mathrm{C}$. The fitted straight line is used to derive the band gap.

\section{List of Tables}

Table I: Comparison of resistivity obtained from dc measurements with values obtained from analysis of optical data. The charge carrier concentration obtained from the optical analysis is also given. 


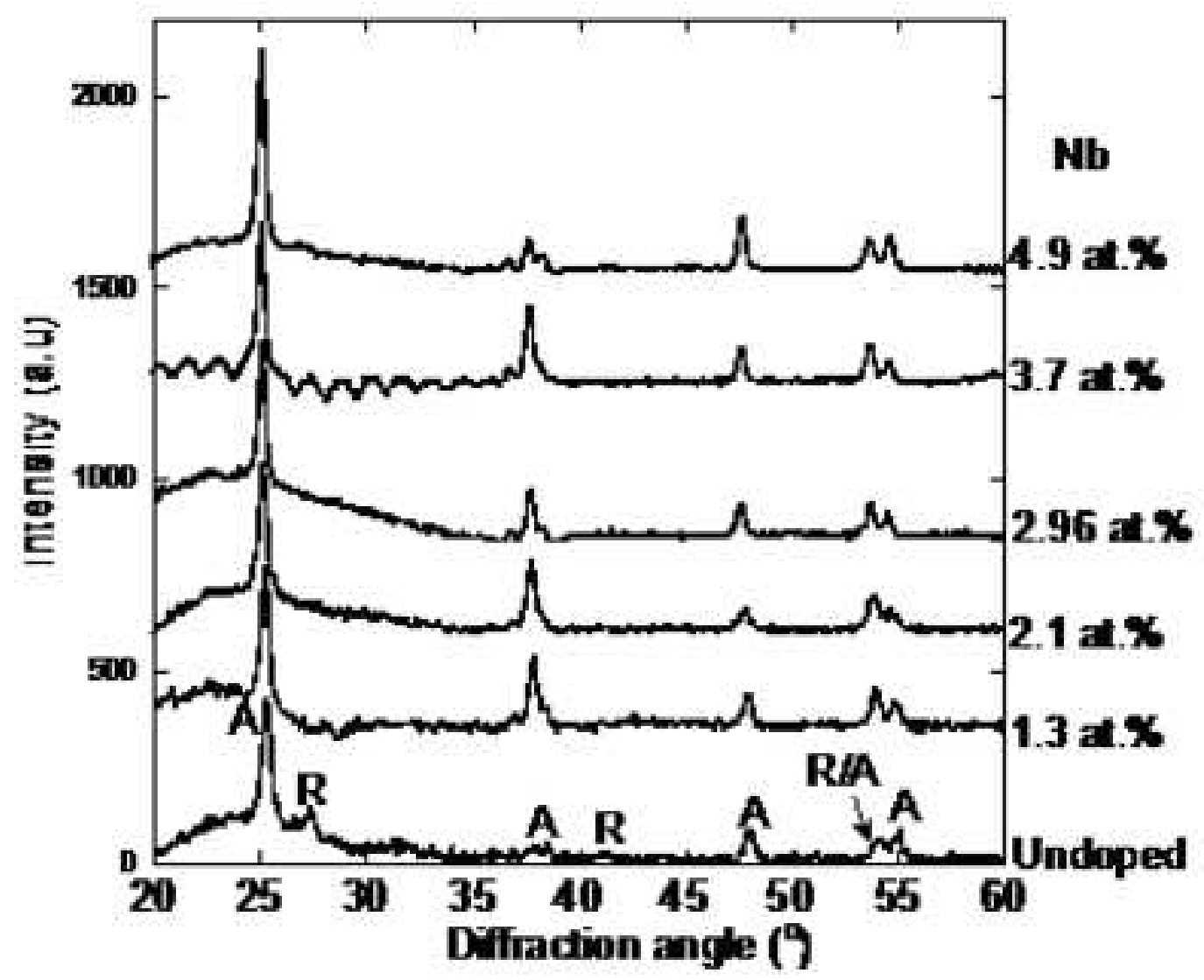




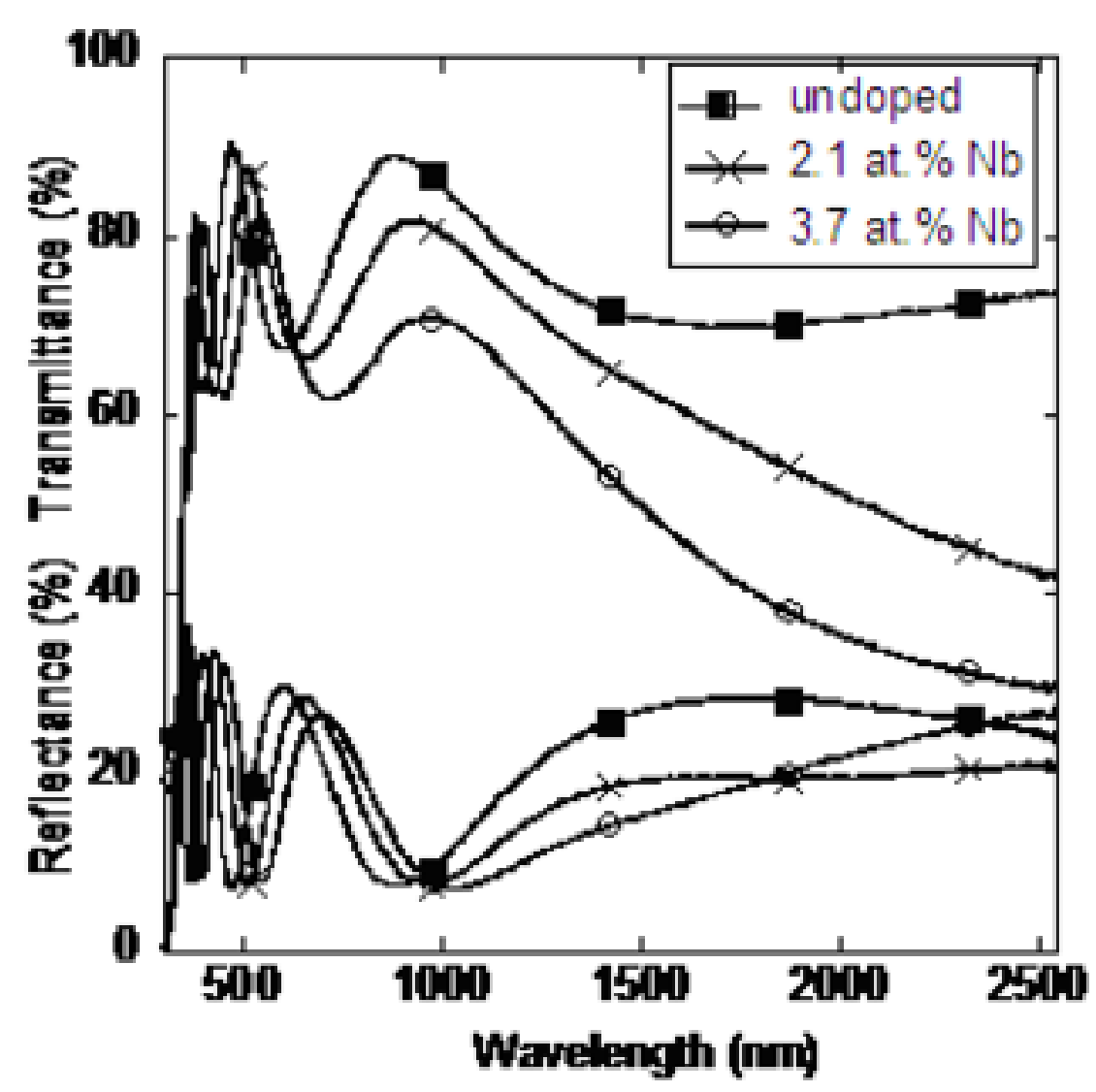



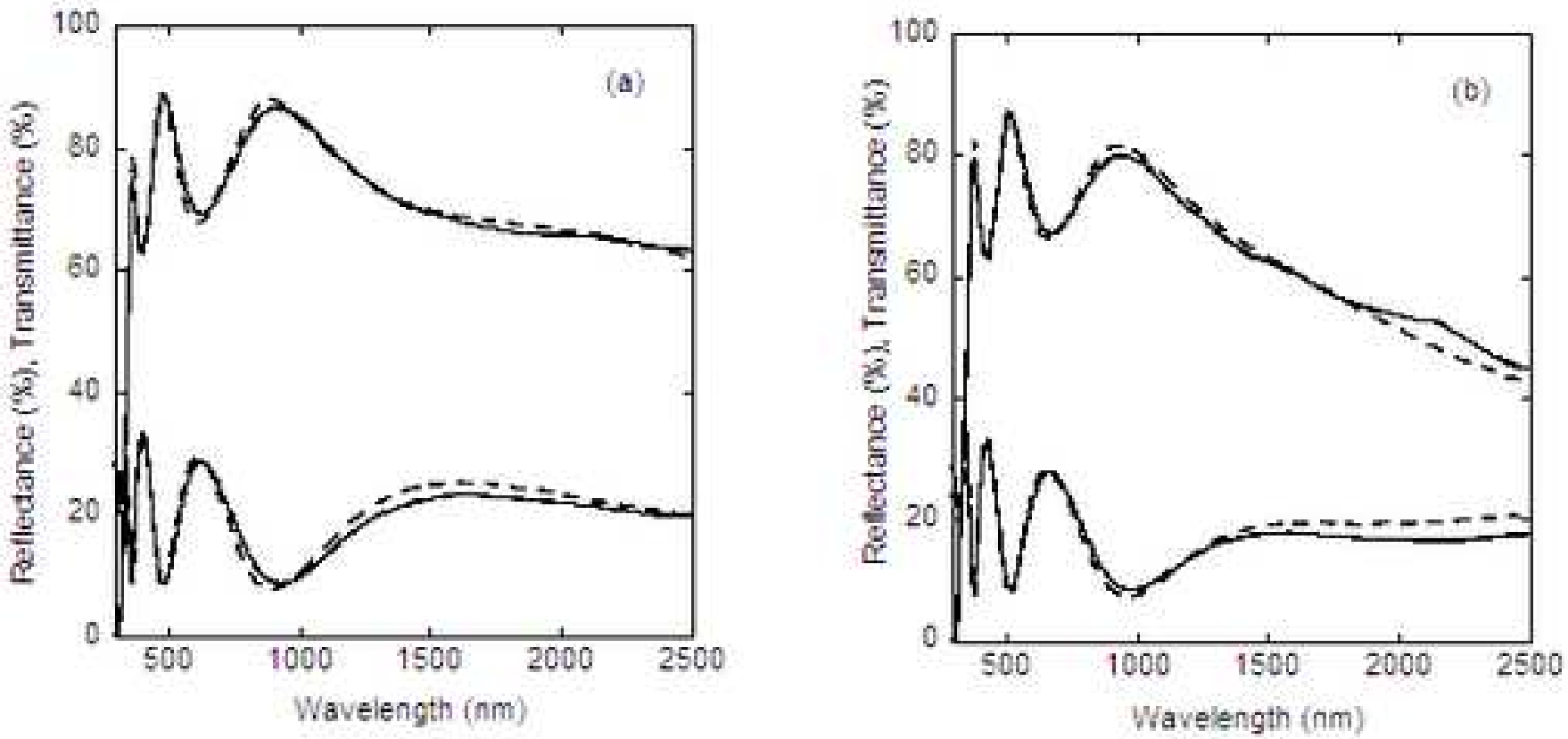

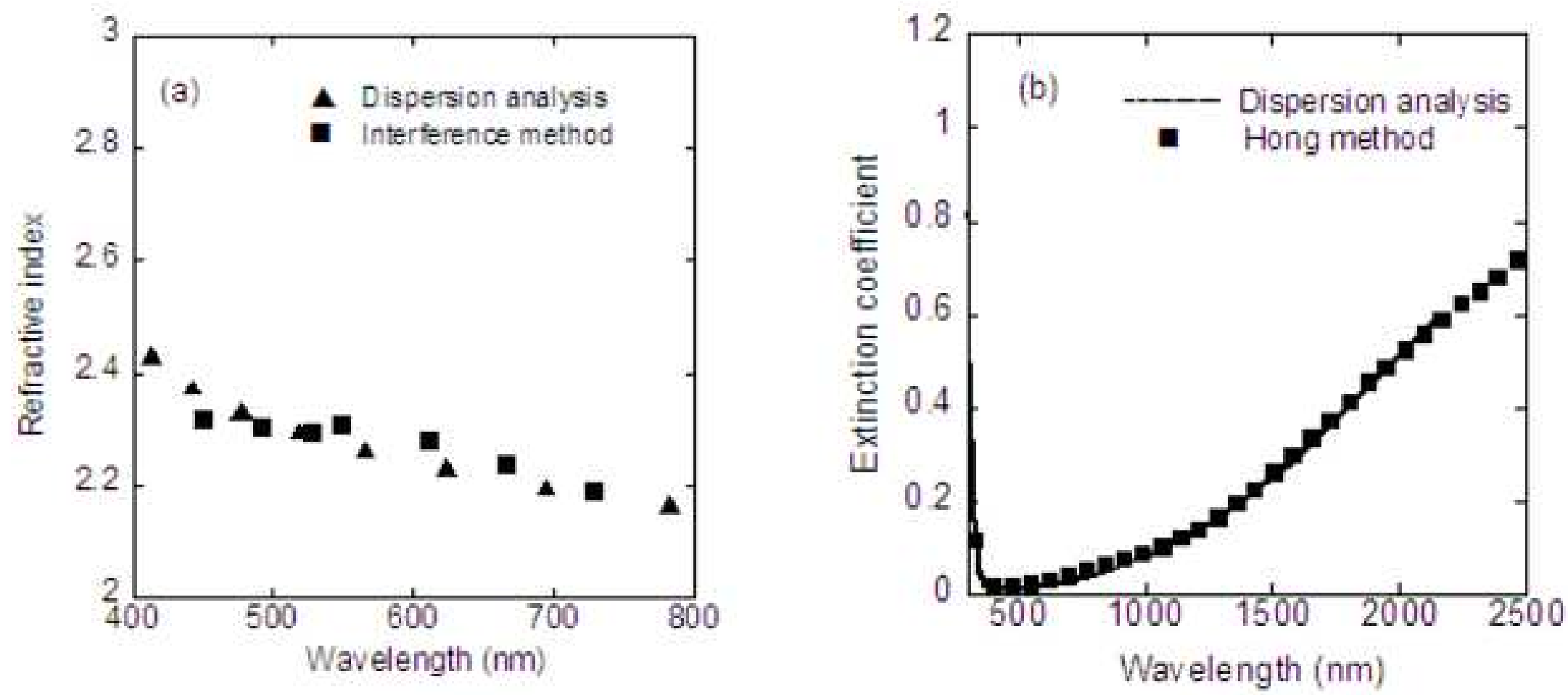

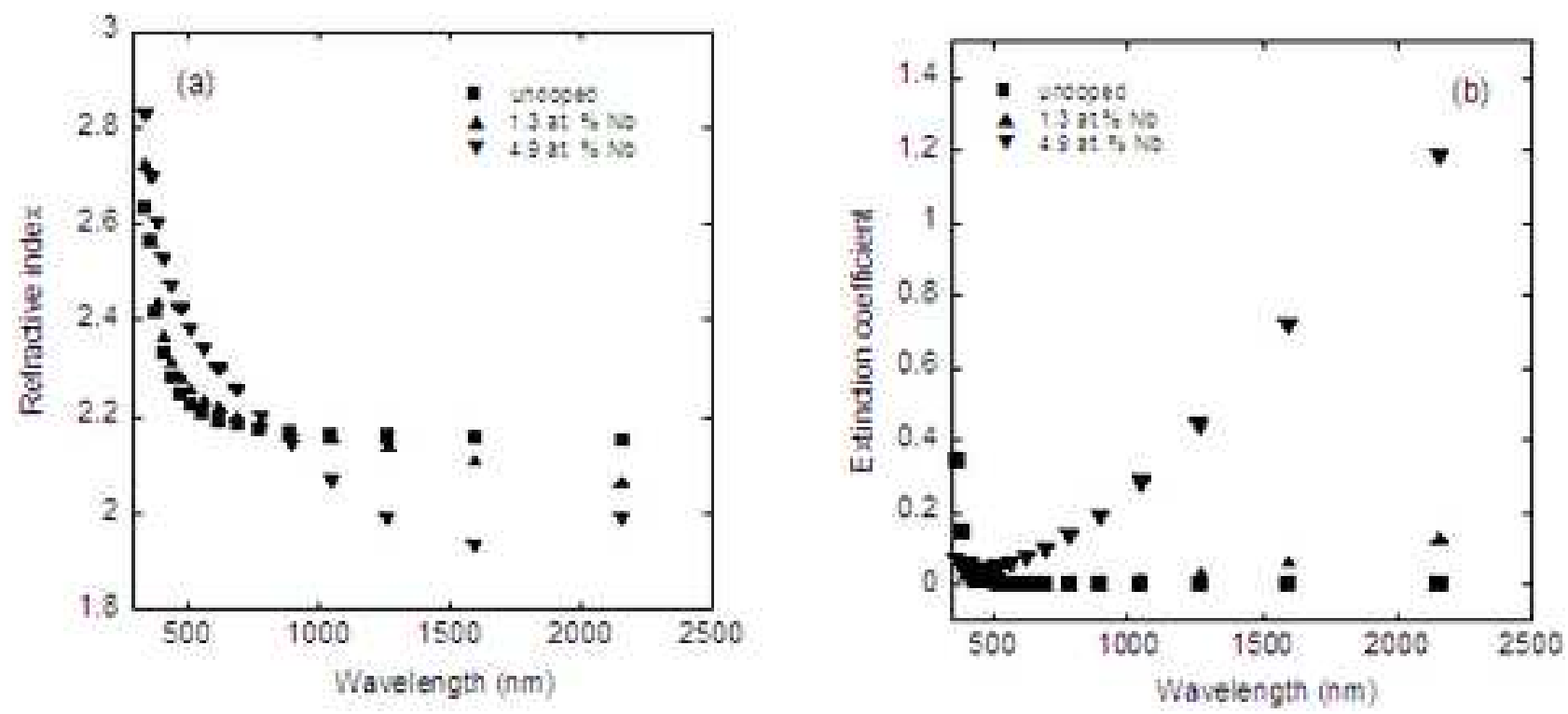


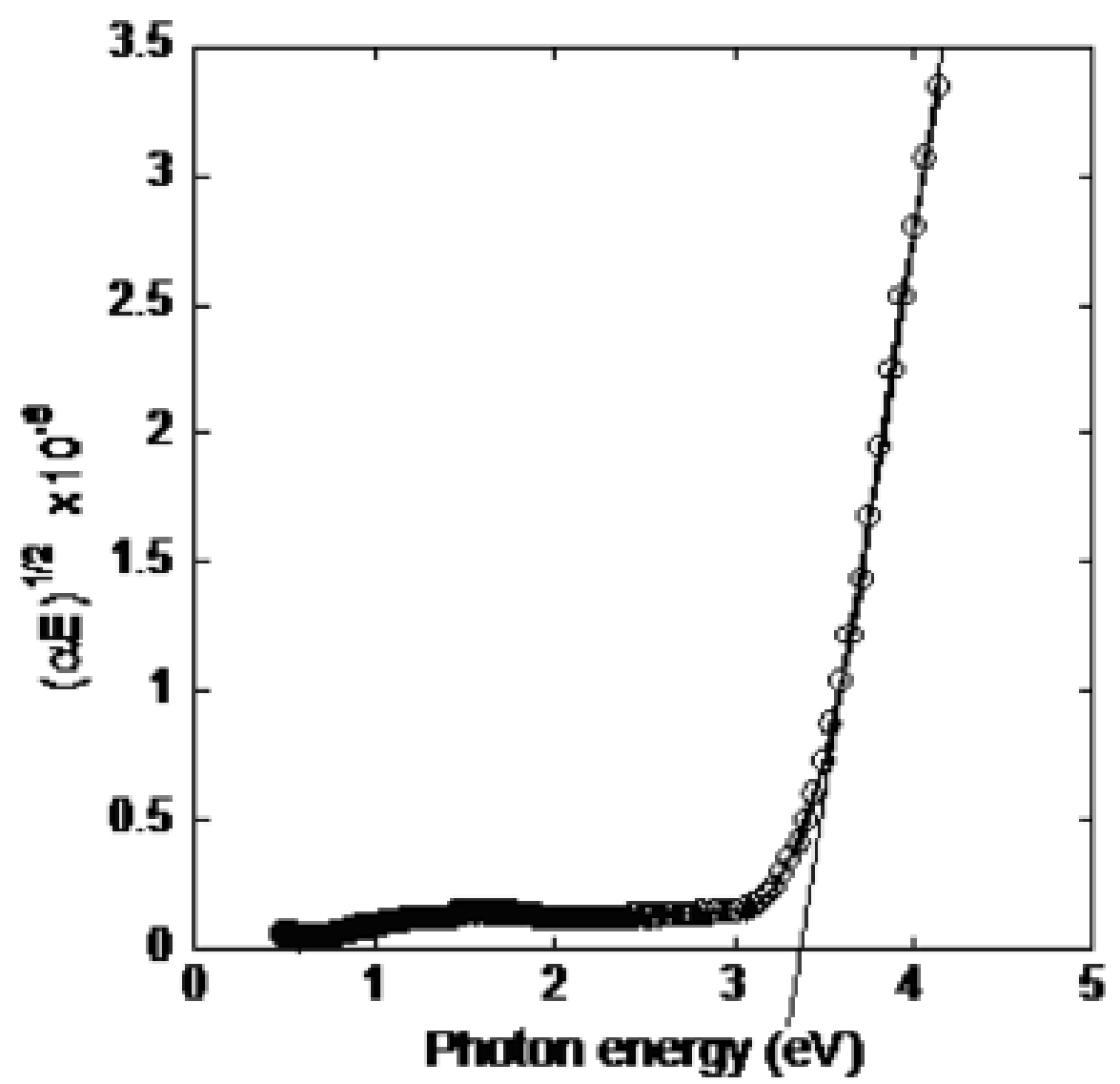




\begin{tabular}{|l|l|l|l|}
\hline \multirow{2}{*}{$\begin{array}{l}\text { Characterization of annealed } \\
\mathrm{TiO}_{2}: \mathrm{Nb} \text { samples }\end{array}$} & \multicolumn{2}{|l|}{ Resistivity $(\Omega \mathrm{cm})$} & $\begin{array}{l}\text { Carrier concentra- } \\
\text { tion }\left(\mathrm{cm}^{-3}\right) \text { (from } \\
\text { optical data) }\end{array}$ \\
\cline { 2 - 4 } & Optical & $\begin{array}{l}\text { Van der } \\
\text { Pauw }\end{array}$ & $9.13 \times 10^{15}$ \\
\hline Undoped $\mathrm{TiO}_{2}$ & $3.31 \times 10^{2}$ & - & $2.5 \times 10^{20}$ \\
\hline 1.3 at. $\% \mathrm{Nb}$ & $1.15 \times 10^{-2}$ & $1.0 \times 10^{-2}$ & $6.0 \times 10^{20}$ \\
\hline 2.1 at. $\% \mathrm{Nb}$ & $6.00 \times 10^{-3}$ & $6.00 \times 10^{-3}$ & $1.06 \times 10^{21}$ \\
\hline 2.96 at. $\% \mathrm{Nb}$ & $3.76 \times 10^{-3}$ & $3.6 \times 10^{-3}$ & $1.25 \times 10^{21}$ \\
\hline 3.7 at. $\% \mathrm{Nb}$ & $3.46 \times 10^{-3}$ & - & $2.41 \times 10^{21}$ \\
\hline 4.9 at. $\% \mathrm{Nb}$ & $1.92 \times 10^{-3}$ & - & \\
\hline
\end{tabular}

